\title{
Carotid Angioplasty
}

\author{
Parth Shah and Michael Dahn \\ Department of Surgery, Section of Vascular Surgery \\ University of Connecticut Health Center, Farmington, CT
}

USA

\section{Introduction}

Carotid intervention for the amelioration of symptoms due to carotid stenosis has been a controversial therapeutic concept for much of its history. Operative carotid surgery (carotid endarterectomy) underwent considerable turmoil and challenge during the late 20th century, eventually becoming a generally accepted approach in the management of symptomatic critical carotid artery stenosis. A similar circumstance currently confronts carotid angioplasty. Carotid endarterectomy (CEA) now represents the clinical standard against which any carotid intervention is compared and carotid angioplasty must "measure up" to this reference procedure. However, it must be recognized that the time line for acceptance of CEA measured approximately 40 years suggesting that the clinical community must exercise patience in the evaluation of carotid angioplasty which enjoys a relatively short history. Conversely, there is considerable vested interest by several specialties for carotid angioplasty to be accepted (cardiology, radiology) or rejected (vascular surgery) indicating the need for critical analysis of this procedure's efficacy. This process of procedure assessment remains a difficult task in view of the constantly changing technological advances that surround this field. This chapter focuses on the key elements of technique and clinical experience which represent the status of carotid angioplasty today.

\section{History}

The association of carotid artery blood flow to the brain as a vital element to sustain neurologic function dates back to Hippocrates (Figure). As a corollary, it has become accepted that atherosclerotic disease of the carotid artery is associated with stroke. This concept was first described by Ramsay Hunt in 1914 and subsequently popularized as one of the most significant risk factors for developing stroke. It wasn't until the 1950's, when durable reconstructive carotid surgery was described and further refined and popularized by Debakey, Eastcott, Rob, Thompson, Moore, Baker and Wylie, that the field of carotid intervention was popularized. Some of the landmark large randomized controlled trials like North American Symptomatic Carotid Endarterectomy (NASCET) ${ }^{1}$, Asymptomatic Carotid Atherosclerosis Study (ACAS) ${ }^{2}$ and European Carotid Surgery Trial (ECST) ${ }^{3}$ showed statistically significant reductions in stroke in the patients undergoing carotid endarterectomy versus medical treatment alone. 
Currently, there are approximately 165,000 carotid endarterectomy (CEA) procedures performed across United States annually and this procedure is considered the "gold standard" for revascularization of the internal carotid artery due to atherosclerotic stenosis.

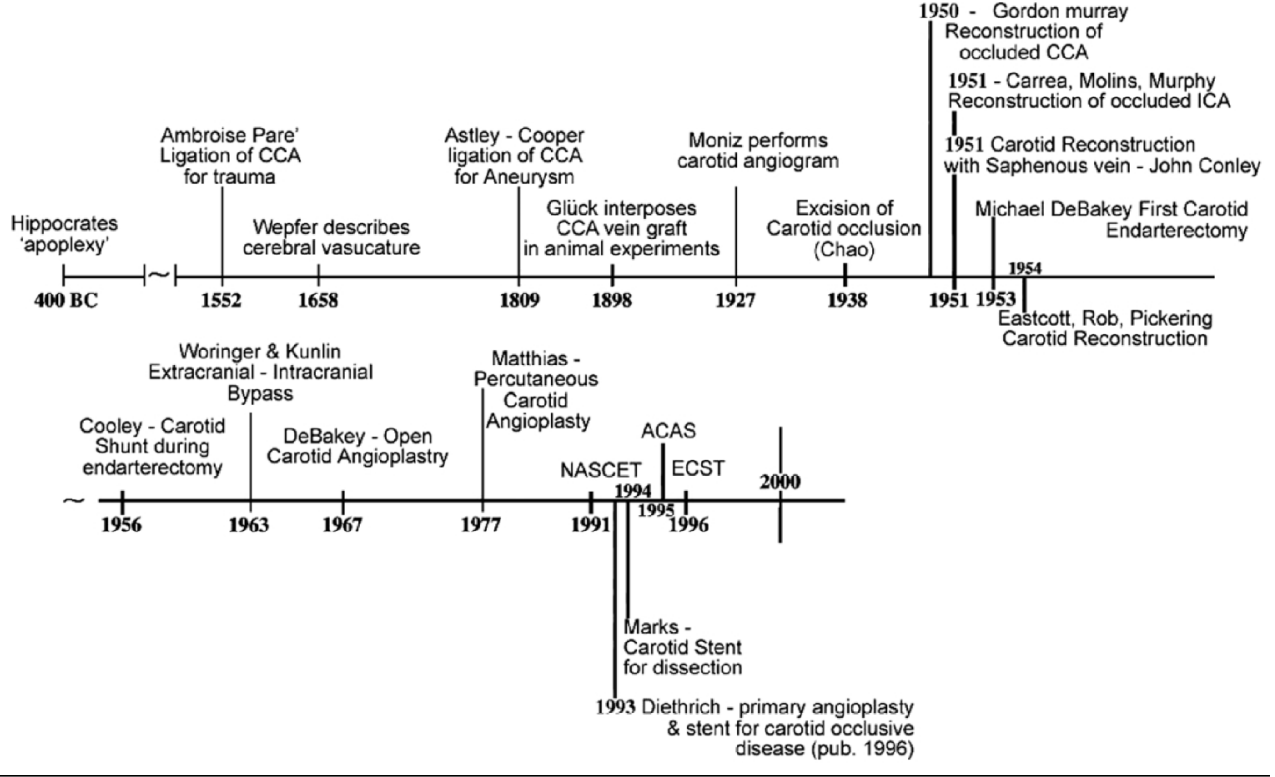

Adapted From Hippocrates to Palmaz-Schatz, the history of carotid surgery. ${ }^{4}$ Robicsek F, Roush TS, Cook JW, Reames MK. Eur J Vasc Endovasc Surg. 2004 Apr;27(4): 389-97.

Moniz described carotid and cerebral angiography in 1927 and thereafter, further improvements in the extracranial carotid imaging facilitated more patients being diagnosed with occlusive carotid diseases and hence treatment advancement. Debakey and his coworkers described intraluminal angioplasty of the internal carotid artery in 1968 for fibromuscular dysplasia. ${ }^{5}$ Percutaneous transluminal angioplasty of carotid artery was described in 1977 by Mathias ${ }^{6}$ and subsequently Diethrich ${ }^{7}$ reported the first large series of carotid angioplasty and stenting in 1995, although the risk of neurological complication was as high as $10.7 \%$ in his report. Subsequently, multiple technical advances have taken place in percutaneous carotid artery interventions including stent augmentation of carotid angioplasty, routine use of cerebral embolic protection and improved patient selection.

Carotid angioplasty and stenting (CAS) provides a few advantages over traditional CEA including avoidance of a neck incision, general anesthesia and freedom from cranial nerve injuries. These benefits have sustained the evolution of CAS over the last 20-30 years. 


\section{Technical aspects of carotid angioplasty and stenting}

Key for successful endoluminal intervention is patient evaluation and proper patient selection, choice of optimum vascular access site, a thorough evaluation of the access route, any anatomic or morphologic anomalies, appropriate selection of devices and accurate sizing of the target lesion and vessels.

Pre-procedural assessment of carotid artery disease is obtained by duplex ultrasound (DU). DU allows an assessment of the degrees of stenosis and extent of calcification. Highly calcified lesions may be more embologenic or unyielding to balloon angioplasty resulting in a suboptimal dilatation. Further information on the target lesion may be obtained by magnetic resonance (MR) or computed tomographic (CT) arteriography. These two imaging modalities are useful confirmatory studies following duplex imaging and offer an assessment of unsuspected occlusive disease outside the DU imaging window. Furthermore, these non-invasive means evaluate access site, aortic arch morphology and any incidental pathology in the access route which are invaluable in the planning of a procedure.

\section{Aortic arch configuration}

Initially, a 4 or $5 \mathrm{Fr}$ sheath access is obtained in the common femoral artery. A flush pigtail catheter may be positioned in the ascending aorta for the initial arch aortogram which is performed in left anterior oblique (LAO) position. Depending on the degree of tortuosity and configuration of the aortic arch, we like to have between 30 degrees to as much as 60 degrees of LAO projection. The performance of the arch angiogram is useful to identify the target vessel origin. In difficult anatomic arrangements, the aortogram is very helpful but it may also increase procedure morbidity. Utilizing diffusion weighted MRI imaging, silent microembolic lesions are detectable in up to two-thirds of patients undergoing $\mathrm{CAS}^{8}$. At least half of these lesions can be identified in the cerebral hemisphere contralateral to the target lesion. This suggests that manipulation of devices, including diagnostic catheters used for arch angiography, are a substantial source of embolic events during CAS.

The aortic arch configuration varies due to multiple patient factors. Probably the dominant factor is age since the aorta tends to elongate with increasing age contributing to a worsening of the arch type. There are mainly three arch types depending on the radiographic morphology (Figure).

\section{Diagnostic catheters}

Safe selective cannulation of the great vessels is the rate-limiting step. Usually the appropriate diagnostic catheters are available in $100 \mathrm{~cm}$ to $125 \mathrm{~cm}$ lengths. The longer lengths are required should one use the telescoping technique (vida infra).

For the Type I aortic arch, the standard angled catheters like the angle taper Glidecath ${ }^{\circledR}$ (Terumo Medical Corporation, Somerset, NJ, USA) or a Berenstein catheter (Boston Scientific, Natick, MA, USA) or Headhunter or JB 1 (Cook Medical, Bloomington, IN, USA) are usually successful.

For more challenging aortic arch morphology, with types II and III configuration, reversecurve catheters like Simmons type catheters (I or II), JB 2 or the VTK catheter (Cook Medical, Bloomington, IN, USA) may be used. 

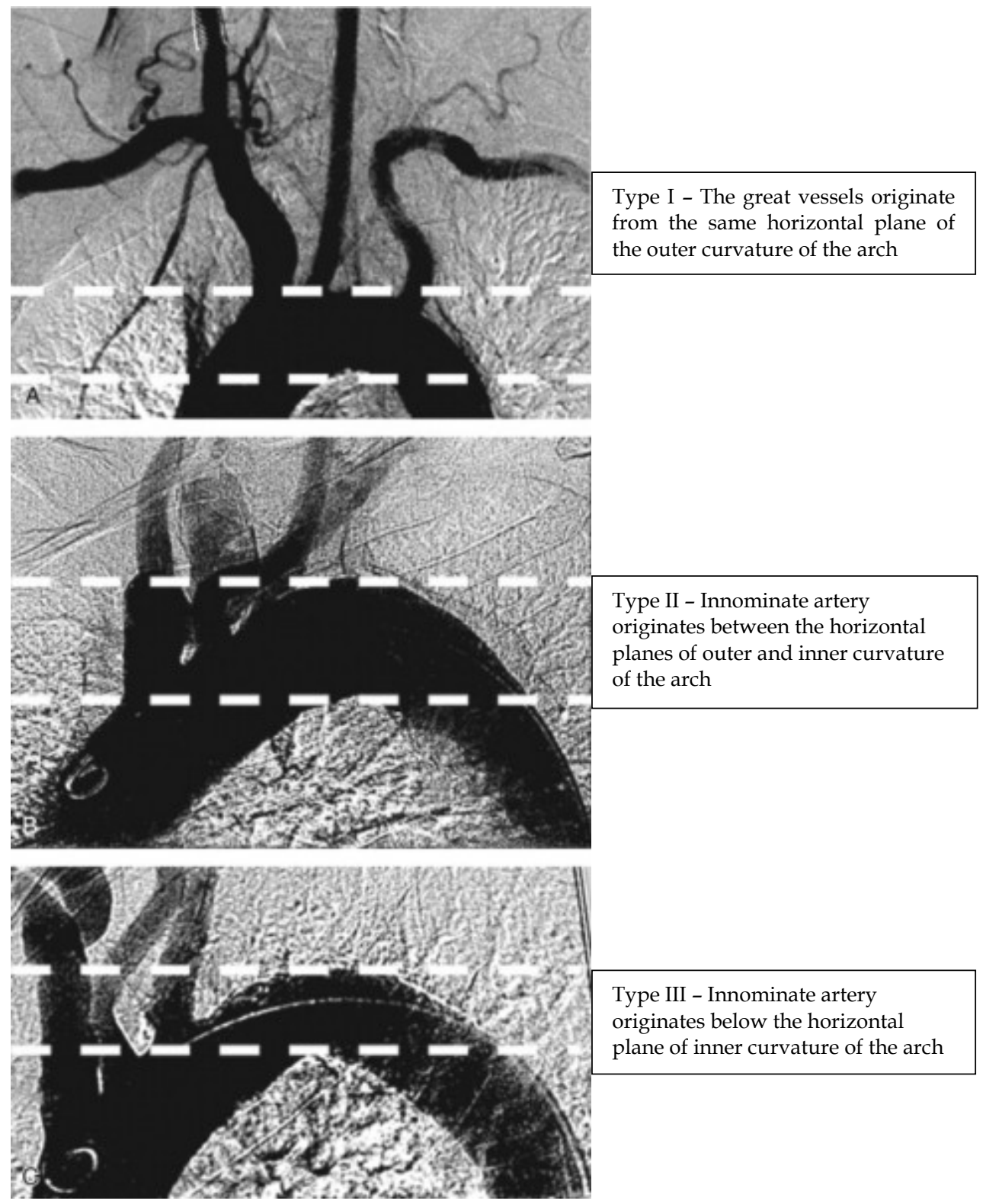

A Type IV arch is a term that may be applied to an exaggerated Type III arch with severe angulation of the great vessels. 


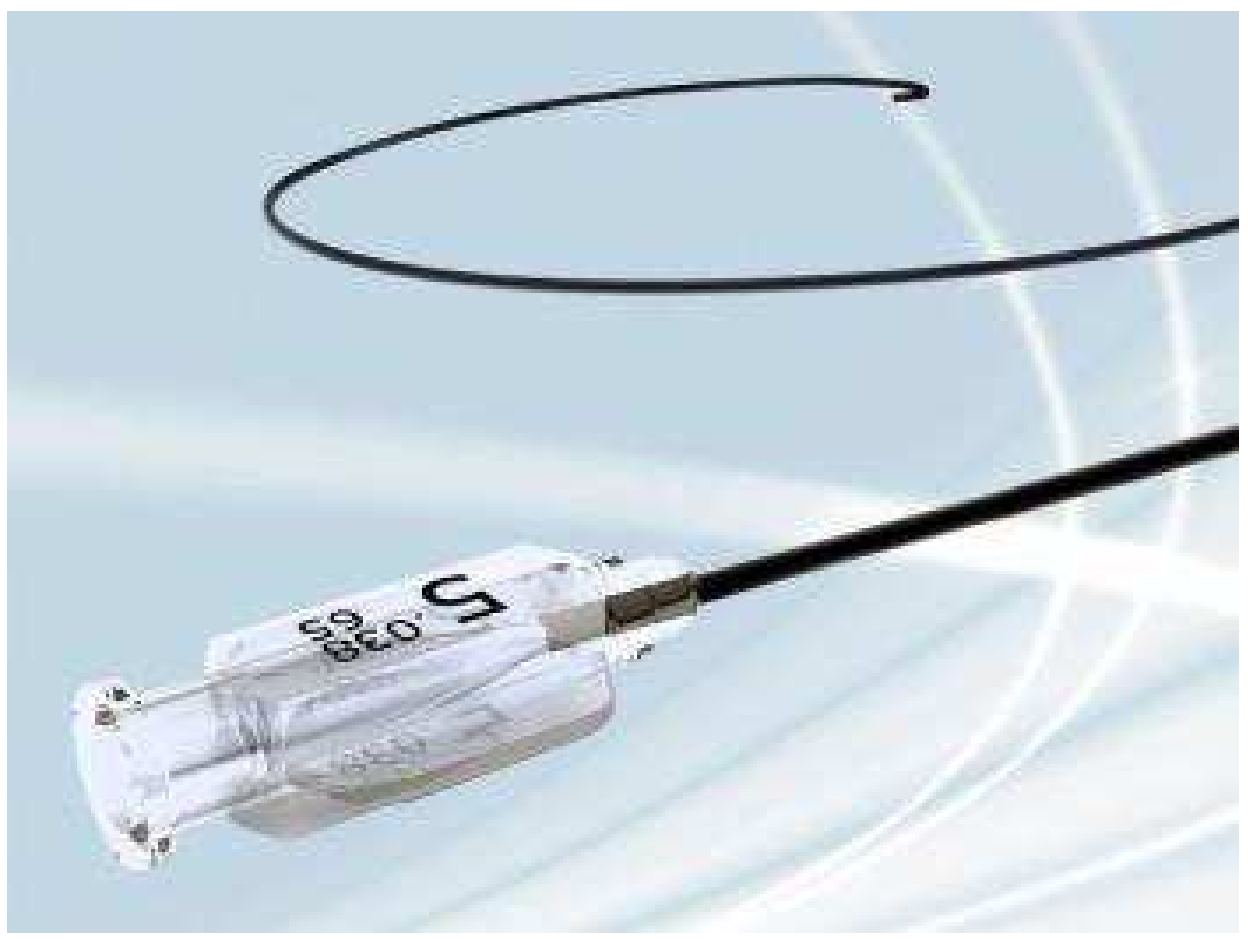

Glidecath ${ }^{\circledR}$
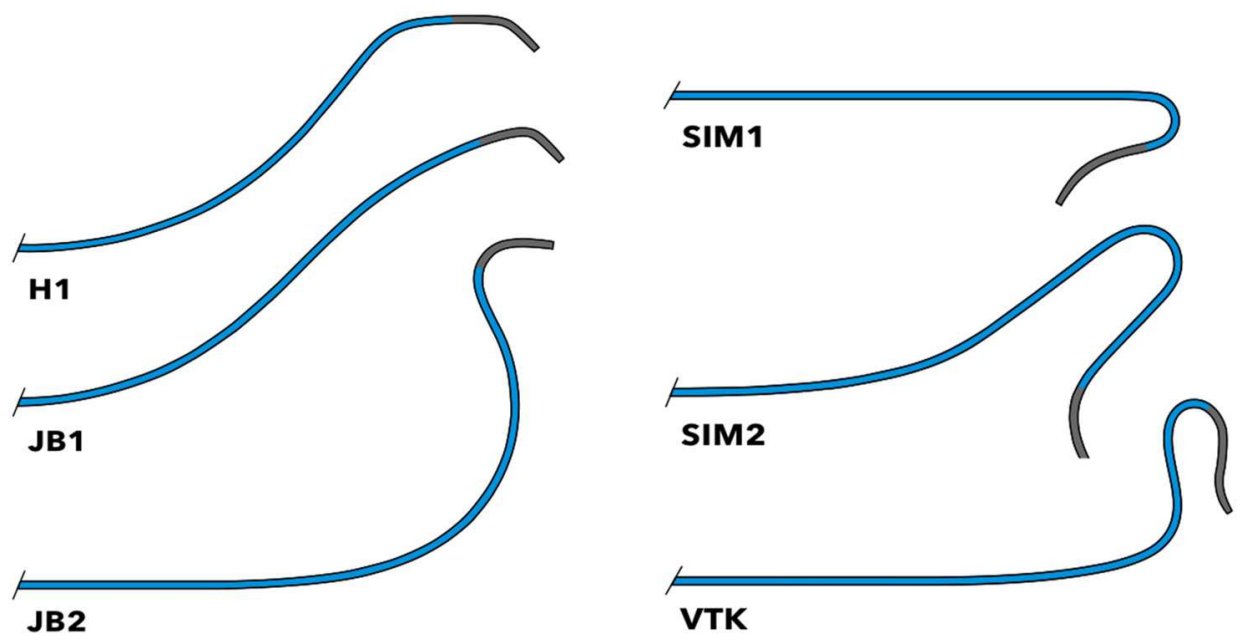

These are the configurations of some of the catheters commonly used in the carotid angioplasty procedure. 


\section{Sheath access}

Positioning of a sheath in the CCA is a prerequisite to CAS. Typically, this requires placement of a diagnostic catheter into the CCA followed by advancement of a glide-wire into the ECA. This allows introduction of the catheter into the ECA followed by a wire exchange for a stiff wire forming the guide for a 6 Fr Shuttle sheath. Occasionally, the ECA is occluded or severely diseased requiring the use of a stable stiff wire access into common carotid artery (CCA) alone and a 6 Fr sheath is advanced and parked into proximal CCA.

\section{Cannulation of internal carotid artery}

After obtaining stable sheath access into proximal CCA, the embolic protection device (EPD) is deployed into the appropriate position. The pros and cons of different cerebral EPDs are discussed in next section.

The different approches of obtaining ICA access depend upon the degree of stenosis, amount of tortuosity and type of EPD used. Usual access to the ICA is obtained with a standard 0.014" wire or EPD dedicated wire followed by delivery of the balloon and stent system.

\section{Telescoping catheter technique}

Positioning of the Shuttle sheath system into the CCA is a prerequisite for the CAS procedure. Typically, this is performed over a stiff wire anchored in the ECA. However, advancement of the stiff wire into the CCA through a diagnostic catheter may be a challenge. If tortuous anatomy prevents this maneuver, a softer, $125 \mathrm{~cm} 6$ or $6.5 \mathrm{Fr}$ catheter is used to replace the obturator of the Shuttle sheath. The additional $35 \mathrm{~cm}$ lead portion of this catheter which is telescoped into the $90 \mathrm{~cm}$ Shuttle serves as a sufficient support over which to slide the sheath once the catheter tip is introduced into the CCA. Thus, the inner catheter effectively serves as a "stiff guide".

\section{Right brachial/axillary artery access technique (double wire technique)}

Access to the right carotid system can be achieved under essentially all anatomically difficult circumstances with this technique. This approach has been successful even with an exaggerated Type III aortic arch configuration (effectively a Type IV arch). The technique requires gaining access to the brachial or axillary artery on the right with passage of an exchange length glide wire retrograde into the thoracic aorta. The wire is snared from a femoral access point for through and through wire control. A 7 or $8 \mathrm{Fr}$ sheath is now advanced into the innominate artery. The wire may be changed out for a smaller wire to reduce occupied space within the sheath while stabilizing it. This is then followed by the transfemoral advancement of a second steerable 0.014 " wire into the CCA. The second wire now permits the delivery of a cerebral protection system and completion of the CAS procedure.

\section{Transtemporal technique}

Access to the CCA can be quite difficult if the carotid anatomy is tortuous or the aortic arch type is unfavorable. The transtemporal approach may be used on either side but it has its 
greatest utility on the left since the right CCA can be cannulated using the double wire technique noted above. The transtemporal approach involves ultrasound guided access or direct dissection of the superficial temporal artery followed by retrograde placement of a coronary wire into the aorta where it is snared from the femoral artery. This provides through and through access permitting advancement of a Shuttle sheath into proper position for the CAS procedure. The remainder of the procedure is then performed in the usual fashion.

\section{Ultra-critical stenosis}

Sometimes the standard 0.014 " wire is not successful in traversing an ultra-critical stenosis, in which case a 0.012" Headliner ${ }^{\circledR}$ Glidewire ${ }^{\circledR}$ (45 degrees, $200 \mathrm{~cm}$ ) (Terumo Medical Corporation, Somerset, NJ, USA), supported by 1.9 Fr (0.026") Prowler ${ }^{\prime \prime}$ microcatheter (Cordis, Miami Lakes, FL, USA) may be successful. Following traversal of the lesion with the microcatheter, the 0.012 " wire is replaced with a more supportive 0.014 " wire which can be parked in the treatment area. The new wire may now be used to deliver a balloon, EPD or a flow arrest/reversal system (vida infra) for completion of the CAS. 9

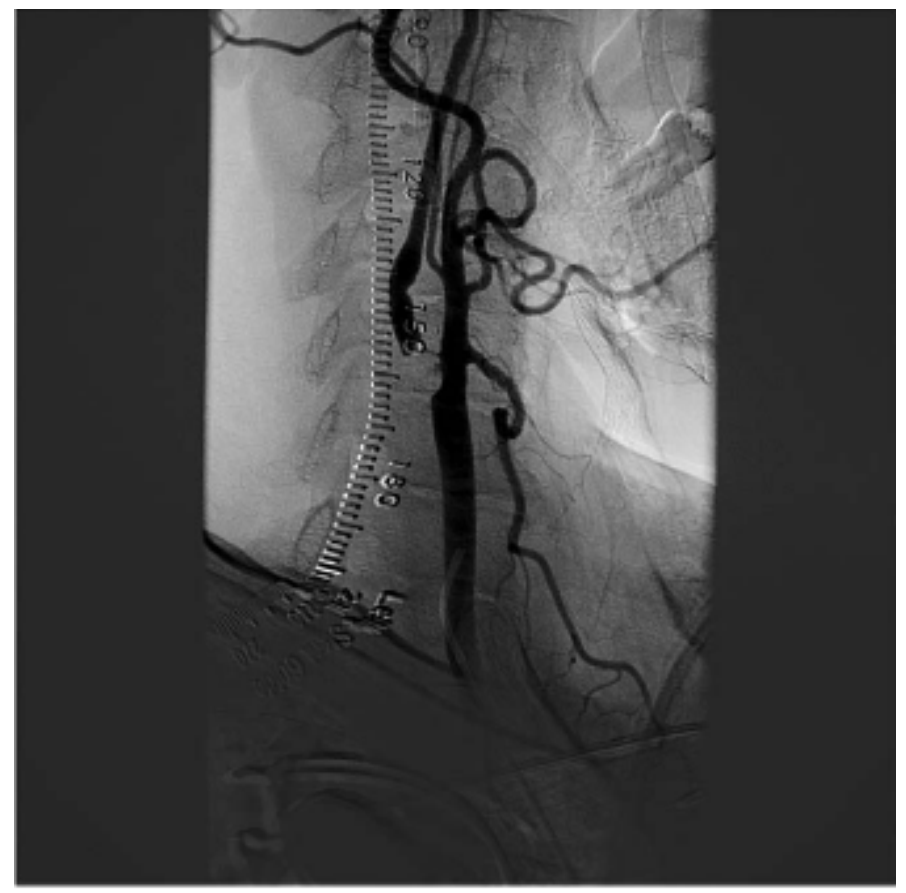

This figure shows a pre-occlusive lesion of the right internal carotid artery which would not accept a $0.014^{\prime \prime}$ wire. 


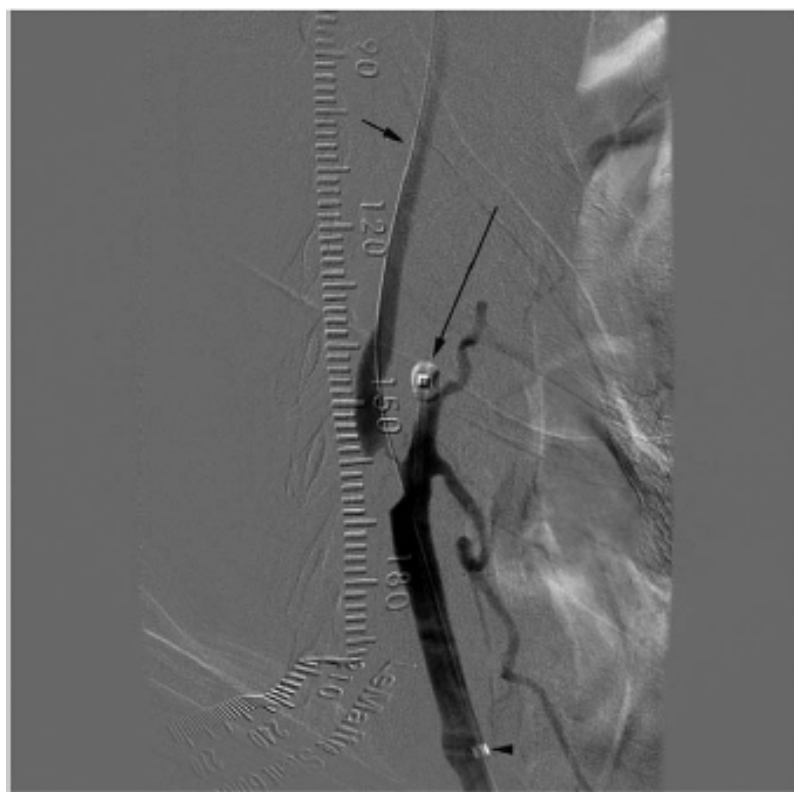

The lesion has been passed using an $0.012^{\prime \prime}$ wire followed by replacement with an $0.014^{\prime \prime}$ wire and placement of a MOMA flow arrest device within the external carotid artery balloon inflated (long arrow).

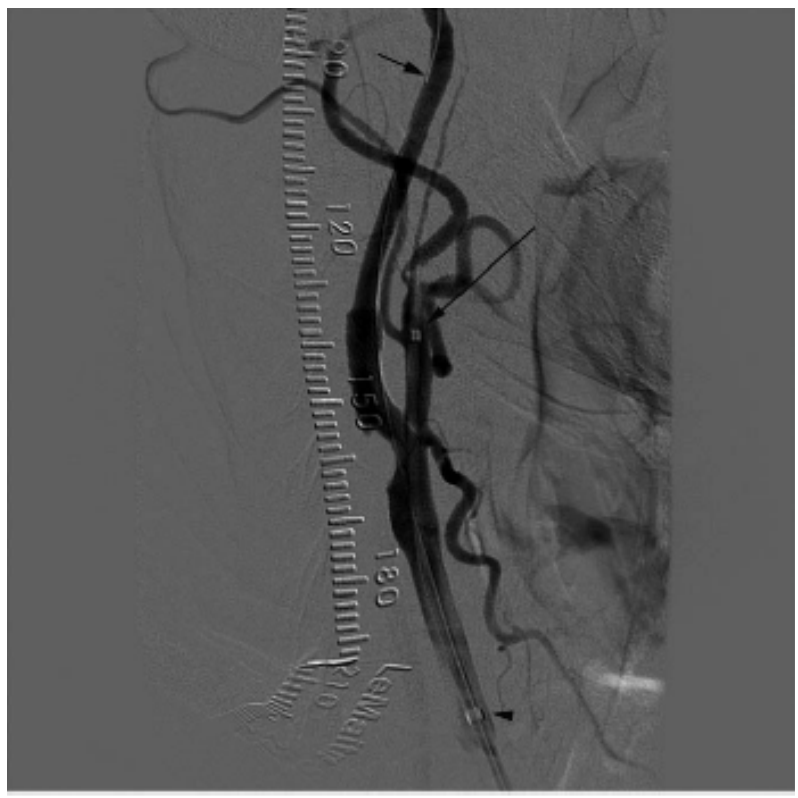

The ICA angioplasty is complete. The MOMA flow arrest device is still in place with the ECA and CCA balloons deflated and flow re-established to the brain. 


\section{Transcervical occlusion and protective shunting technique}

This technique uses a partially open operative approach. The procedure is performed under local anesthesia utilizing a small incision just above the clavicle. A large $(9 \mathrm{Fr})$ and medium (6 Fr) sheath are introduced into the CCA directed in a cephalad orientation through the incision. Additionally, a $6 \mathrm{Fr}$ sheath is introduced into the jugular vein directed caudally. An over-the-wire fogerty catheter is used to occlude the external carotid artery and the proximal CCA is clamped following anticoagulation. Flow reversal in the carotid system is established by connecting the sideports of the $9 \mathrm{Fr}$ arterial and $6 \mathrm{Fr}$ venous sheaths and flow direction is verified using a small injection of contrast. Now, the angioplasty is performed through the $9 \mathrm{Fr}$ sheath and any loose debris that results is carried into the venous system or trapped by any interposed filter. The arterial puncture sites are sutured at the time of final sheath removal. This approach appears fairly labor intensive within a small field and the use of a partially open portion of the angioplasty procedure seems to defeat the minimally invasive nature of CAS. Nonetheless, it has been suggested as a reliable means of controlling embolization.

\section{Review of literature}

Mathias first described the percutaneous carotid artery angioplasty (CA) technique in 1977.10 Subsequently he reported a case series of 3 high surgical risk patients undergoing percutaneous carotid angioplasty. ${ }^{11}$ During this time, percutaneous carotid intervention was limited to fibromuscular dysplasia and was not applied to atherosclerotic diseases due to risk of embolic events and secondly, CEA was considered a very safe procedure and its utilization was widespread. There were occasional case reports of CA, but it wasn't until 1990's when this technique was more systematically studied for its feasibility, safety and outcomes. The summary of early clinical studies is shown in Table 1 . The most feared complication of CA is embolic phenomenon and evidence of early and delayed embolization after percutaneous CA was reported by Markus et al. ${ }^{12}$

\begin{tabular}{|l|c|c|c|c|}
\hline & $\begin{array}{c}\text { Study number } \\
\text { (Follow-up) }\end{array}$ & $\begin{array}{c}\text { Technical } \\
\text { success }\end{array}$ & Stroke & $\begin{array}{c}\text { Overall complications } \\
\text { (MI/Stroke/Death) }\end{array}$ \\
\hline Diethrich EB ${ }^{13}(1996)$ & $110(7.6$ months) & $99 \%$ & $12(10.9 \%)$ & $12(10.9 \%)$ \\
\hline Roubin GS14 $(1996)$ & $146(6$ months) & $99 \%$ & $9(6 \%)$ & $11(7.5 \%)$ \\
\hline Gil-Peralta A ${ }^{15}(1996)$ & $85(18.7$ months) & $91.8 \%$ & $7(8.6 \%)$ & $7(8.6 \%)$ \\
\hline Yadav JS16 $(1997)$ & $107(6$ months) & $100 \%$ & $9(8.4 \%)$ & $10(9.3 \%)$ \\
\hline Jordan WD, Jr17 $(1997)$ & $107(6$ months) & NA & $9(8.4 \%)$ & $10(9.3 \%)$ \\
\hline Vozzi CR ${ }^{18}(1997)$ & $22(10$ months) & NA & $2(9 \%)$ & $2(9 \%)$ \\
\hline Teitelbaum GP19 $(1998)$ & $25(6$ months) & $96.2 \%$ & $2(7.7 \%)$ & $6(27 \%)$ \\
\hline
\end{tabular}

Table 1.

In 1992, Brown ${ }^{20}$ reviewed approximately 100 cases reported in the literature with stroke rate of $4 \%$. In May 1998, Wholey ${ }^{21}$ published a review of 2,048 cases of carotid stents across 24 centers world-wide and reported a $98.6 \%$ technical success rate. Also the complication rates were $3.08 \%$ for minor strokes, $1.32 \%$ major strokes and $1.37 \%$ peri-procedural mortality. The 6-month re-stenosis rate was $4.8 \%$ by duplex-ultrasound or angiographic method. The stents being utilized for carotid stenting at the time were Palmaz (Cordis) or 
Palmaz-Schatz (Johnson and Johnson) balloon expandable stents (53\%), followed by Wallstent (Schneider, Minneapolis, MN) (39\%), Strecker (8\%) and Inegra (1\%) (Medi-Tech) stents. Subsequently, he reported updated data for 5,210 cases across 36 centers in June 2000. This showed a rapid rise in global popularity of this procedure. The incidence of major and minor stroke remained $1.49 \%$ and $2.72 \%$. This review observed lower stroke rates in the centers with more than 50 procedures performed indicating the importance of a learning curve. Overall procedure-related complication rates declined from $5.72 \%$ in 1998 to $4.75 \%$ in 2000. Since the cerebral protection technology had not yet evolved, these results derived from "unprotected" procedures.

Theron et al 22 first reported the use of cerebral embolic protection in carotid artery angioplasty and stenting procedures. There were no procedure related complications in 136 cases of carotid artery stenting with use of the cerebral embolic protection for atherosclerotic stenosis.

The Carotid Revascularization using Endarterectomy or Stenting Systems (CaRESS) ${ }^{23}$ was a non-randomized prospective trial designed for high-risk patients with or without symptoms. Total of 397 patients were studied and the outcomes at 4-years showed a stroke incidence of $9.6 \%$ in CAS group versus $8.6 \%$ in CEA group $(p=0.444)$ and an overall complication (death/stroke) rate of $26.5 \%$ in CEA versus $21.8 \%(p=0.361$ ) in CAS. However, at the long-term follow-up, there were significantly higher re-stenosis and re-intervention rates in the CAS arm.

\section{Randomized controlled trials}

\subsection{CAVATAS}

In 1996, the European Carotid Angioplasty trial group reported the rationale, design and protocol of the first multicenter randomized trial, the Carotid and Vertebral Artery Transluminal Angioplasty Study (CAVATAS). ${ }^{24}$ Preceding this trial, a single center trial in the UK was stopped after enrolling 20 patients due to unacceptable rate of stroke in the carotid angioplasty arm (7/10 patients). ${ }^{25}$ The CAVATAS trial involved 22 centers across Europe, Canada and Australia and the patient enrollment was between March 1992 and July 1997. Five hundred and four patients were randomized to either CEA or CAS. The majority of patients $(90 \%)$ in both arms had symptoms within 6 months of randomization and exhibited $>70 \%$ carotid stenosis. Because the stents suitable for CAS were developed during the course of this study, all the patients before 1994 had primary balloon angioplasty alone versus the cases thereafter, which utilized stenting with Wallstent (Schneider, Minneapolis, MN), Streker (Medi-Tech, USA) and Palmaz (Johnson and Johnson, USA) stents. High-risk patients were excluded from the study. The major stroke and death rates were not statistically significantly different between two groups (30-day: 10\% for CAS versus $10 \%$ for CEA; 3-years: $14.3 \%$ in CAS versus $14.2 \%$ in CEA). The primary limitation of this study is that very low number of patients $(26 \%)$ who underwent carotid artery stenting and that the stroke and death rates were unusually high. However, subgroup analysis showed the incidence of stroke was only $2 \%$ in the stented patients, which lead to more widespread use of stent application after balloon angioplasty of a carotid artery stenosis.

\section{WALLSTENT ${ }^{26}$}

The Carotid WALLSTENT trial enrolled 223 patients with symptomatic carotid artery stenosis $>60 \%$. No cerebral embolic protection was used. The trial was stopped due to unacceptably high risk of stroke in CAS group $(12.1 \%)$ versus CEA $(4.5 \%, \mathrm{P}=0.022)$. 


\section{Stenting and Angioplasty with Protection of the Patients at High Risk for Endarterectomy (SAPPHIRE) ${ }^{27}$}

This multicenter, industry-supported randomized trial enrolled 747 patients from 29 centers between 2000 and 2002. The major "high-risk" criteria were significant cardiac or pulmonary disease, contralateral carotid occlusion, prior neck radiation or radical neck surgery, recurrent stenosis, contralateral recurrent laryngeal nerve palsy or age greater than 80 years. The study showed that CAS was non-inferior to CEA when evaluating the cumulative incidence of major stroke, MI or death in 30-day period and at 1-year.

\section{Stent-supported Percutaneous Angioplasty of the Carotid artery versus Endarterectomy (SPACE) ${ }^{28}$}

The SPACE trial was designed as non-inferiority trial for CAS versus CEA. 1214 patients with symptomatic high grade stenosis of carotid artery $(>70 \%)$ were randomized into CAS or CEA between March 2001 and February 2006. The primary end-point of ipsilateral stroke or death rate was $6.45 \%$ in CEA group versus $6.92 \%$ in CAS group which did not reach the statistical significance level $(\mathrm{p}=0.09)$ for non-inferiority for CAS. At 2-year follow-up, the overall mortality was $6.3 \%$ in CAS versus $5 \%$ in CEA $(p=0.68)$, and the ipsilateral ischemic stroke rate was $2.2 \%$ vs $1.9 \%$. However, recurrent stenosis ( $>70 \%$ by ultrasound criteria) was $10.7 \%$ in CAS versus $4.6 \%$ in CEA group $(\mathrm{p}=0.0009)$. The subgroup analysis showed patients greater than 68 years of age had higher event rates with CAS compared to CEA, whereas the younger patients did better with CAS compared to CEA.

\section{Endarterectomy Versus Angioplasty in patients with Symptomatic Severe Carotid Stenosis (EVA-3S) trial ${ }^{29}$}

This trial was a French multicenter, prospective randomized non-inferiority trial. The patient enrollment started in November 2000 and ended in September 2005. A total of 527 patients were enrolled and randomized into two arms. All the CAS cases after January 2003 were done with approved EPDs at the time, which left initial 73 cases being done without any cerebral protection. The 30-day risk of stroke or death was 3.9\% in CEA group versus $9.6 \%$ in CAS group, and risk of any peri-procedural disabling stroke or death was $1.5 \%$ in CEA group versus $3.4 \%$ in CAS group. The 4-year hazard ratio (HR) of any disabling or fatal stroke or death was $2.0(\mathrm{p}=0.17)$ slightly favoring endarterectomy. Although the periprocedural risk was unusually higher in the stenting group, overall long-term secondary prevention of stroke was similar in both arms. The major criticism of this study was that despite a requirement of a minimum procedure volume performed prior to enrollment in the study as an operator, overall operator experience was too limited and may have influenced the outcomes.

\section{The International Carotid Stenting Study (ICSS) ${ }^{30}$}

The ICSS study, also known as CAVATAS-2, was designed. A meta-analysis of 3 trials, EVA-3S (2008), SPACE (2008) and the ICSS (2010) showed significantly lower event rate in the CEA group (OR 1.73, 95\% CI: $1.29-2.32)^{20}$. Age, greater than 70 years, was a risk factor for poorer outcomes with CAS $(12 \%)$ compared to CEA $(5.9 \%), \mathrm{RR}=2.04$. However, the patients younger than 70 years had no difference in outcomes. ${ }^{31}$ 


\section{Carotid Revascularization Endarterectomy versus Stenting Trial $(\text { CREST) })^{32}$}

This North American prospective randomized controlled trial enrolled 2502 patients from 117 centers (symptomatic and asymptomatic). The primary end-points of any stroke, MI or death were similar in both groups of CEA (6.8\%) and CAS (7.2\%). Although there was a lower incidence of MI in the CAS group versus lower stroke rate in the CEA group, these rates did not reach statistical significance. Also the younger patients had slightly better outcomes with CAS whereas the older patients did slightly better after CEA. At one year, subgroup analysis revealed that stroke had a lasting effect on quality of life as opposed to the effects of MI. Nonetheless, overall, both procedures were safe when done by a skilled operator.

\section{Cerebral embolic protection devices}

The first safety and feasibility study of the ICA filter devices for cerebral embolic protection was done by Reimers et al. ${ }^{33}$ The 3-types of the filter devices used in that study are shown below.

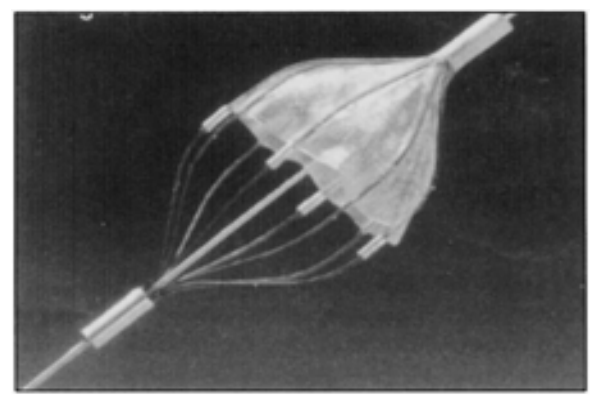

Angioguard

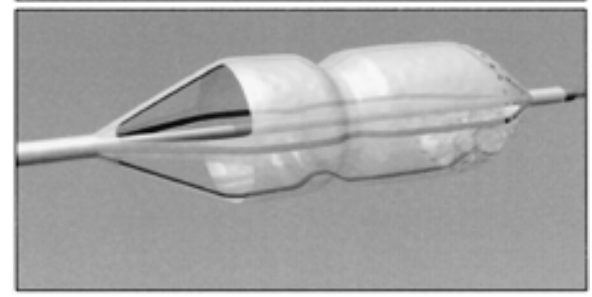

Neuroshield /

Emboshield

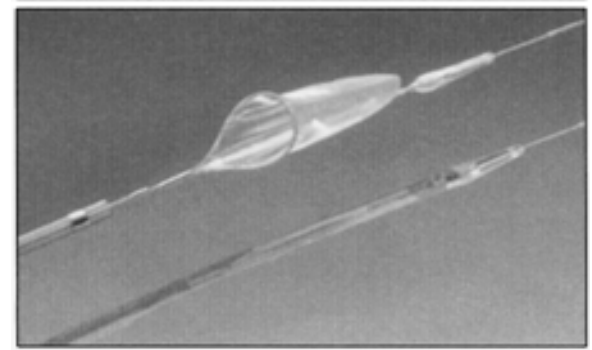

FilterWire EX

Subsequently, the EPD field has expanded with the addition of other filtration systems such as those shown below. All of these devices are based upon a similar principal of flowthrough filtration. 


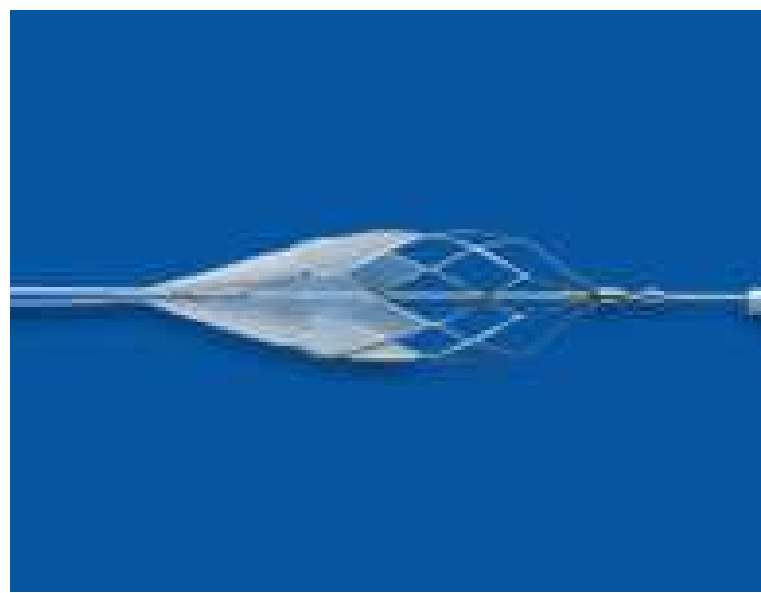

Rx Accunet

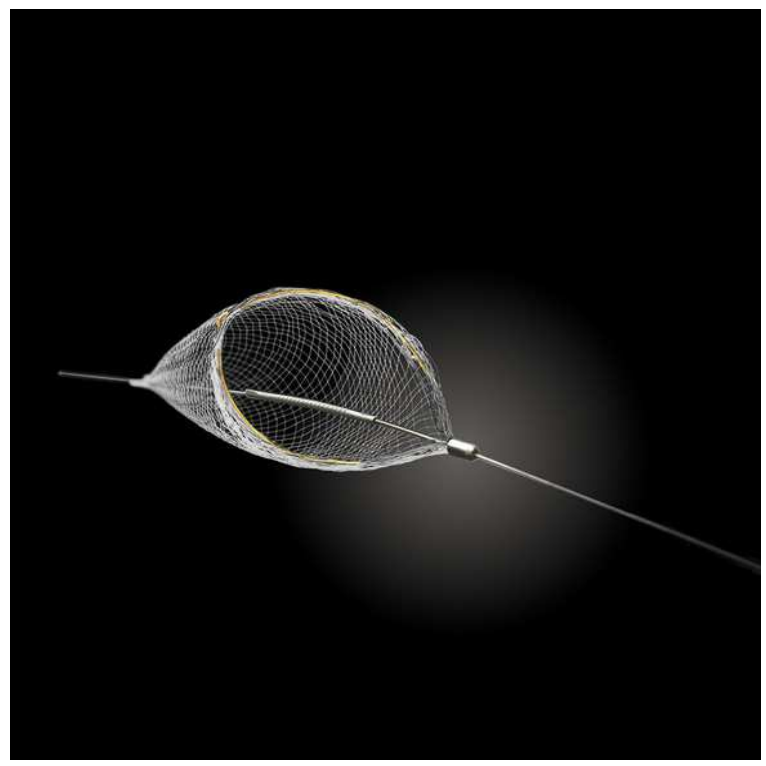

Spider

Overall, there are three major functional principles upon which all EPDs are based. (1) Distal ICA balloon occlusion with flow arrest (2) filtration with continuous flow through (as noted in the above figures), and (3) proximal balloon occlusion with flow stagnation or flow reversal. The pros and cons of these devices are enumerated in Table 2. 


\begin{tabular}{|c|c|c|c|}
\hline Type & Pros & Cons & $\begin{array}{l}\text { Currently available } \\
\text { in Market in the US }\end{array}$ \\
\hline Filter & $\begin{array}{l}\text { Maintains flow throughout } \\
\text { the procedure } \\
\text { Can perform angiogram } \\
\text { during the procedure }\end{array}$ & $\begin{array}{l}\text { Risk of embolism } \\
\text { while traversing the } \\
\text { lesion } \\
\text { Technically difficult } \\
\text { in tortuous vessels } \\
\text { Risk of } \\
\text { microembolism } \\
\text { (smaller than pore } \\
\text { size of the filter) } \\
\text { Risk of filter } \\
\text { thrombosis }\end{array}$ & $\begin{array}{ll}\text { - } & \text { Rx Accunet } \\
\text { - } & \text { Filter-wire } \\
\text { - } & \text { Angioguard } \\
\text { - } & \text { Emboshield } \\
\text { - } & \text { Spider }\end{array}$ \\
\hline $\begin{array}{l}\text { Distal ICA } \\
\text { occlusion }\end{array}$ & $\begin{array}{l}\text { Offers complete distal } \\
\text { embolic protection }\end{array}$ & $\begin{array}{l}\text { Risk of embolism } \\
\text { while traversing the } \\
\text { lesion } \\
\text { Potential for arterial } \\
\text { injury by balloon } \\
\text { Inability of some } \\
\text { patients to tolerate } \\
\text { ICA occlusion } \\
\text { Inability to perform } \\
\text { angiogram during } \\
\text { the procedure }\end{array}$ & - $\quad$ GuardWire \\
\hline $\begin{array}{l}\text { Proximal } \\
\text { occlusion }\end{array}$ & $\begin{array}{l}\text { Does not require traversing } \\
\text { the lesion unprotected } \\
\text { Offers complete distal } \\
\text { embolic protection }\end{array}$ & $\begin{array}{l}\text { Complete flow } \\
\text { arrest or reversal } \\
\text { during the } \\
\text { procedure } \\
\text { Potential for arterial } \\
\text { injury by balloon } \\
\text { Cerebral Intolerance }\end{array}$ & $\begin{array}{ll}- & \text { MO.MA } \\
-\quad & \text { PAES (Parodi } \\
& \text { antiembolism } \\
& \text { system) }\end{array}$ \\
\hline
\end{tabular}

Table 2.

\section{Filter protection}

All filter devices have similar design. The filter is mounted on a 0.014 " wire with floppy tip. The filter is made up from nitinol (nickel-titanium alloy) covered with polyurethane membrane. The porous size of the filter ranges from 30 to 140 microns. Each filter comes in with its own deployment and retrieval sheaths. The filter basket and the sheath are flushed carefully with heparinized saline with particular attention to avoid any air-bubbles. Once the filter is deployed in the distal straight portion of the ICA, the more proximal diseased area is treated over the $0.014 "$ wire. The size of the filter is chosen considering the luminal 
diameter of the distal ICA. At the conclusion of the procedure, the filter is retrieved and then the entire system is removed. The currently available filter-devices have a crossing profile between $3 \mathrm{Fr}$ and $4 \mathrm{Fr}$ and accommodate the vessels from $3 \mathrm{~mm}$ to $7 \mathrm{~mm}$ diameter.

\section{Flow arrest or flow reversal technique}

Embolic protection during CAS can be accomplished with carotid flow arrest or reversal. The MOMA device is a 9 Fr sheath incorporating a small compliant balloon introduced into the ECA and a larger balloon located on the distal main body of the device used for CCA occlusion. Intubation of the ECA is performed using a $0.035^{\prime \prime}$ wire placed during a standard initial approach. The ECA wire serves as a guide for initial device placement. Following anticoagulation, the ECA and CCA balloons are inflated providing for carotid flow arrest. Any standard 0.014 " wire may now be used to deliver angioplasty balloons and stents to the target lesion. An advantage to this system is that the working wire does not need to be advanced deep into the ICA territory thereby making this a favorable method when there is severe tortuosity to the ICA which will not accept distally placed filtration EPDs. Debris in the carotid bulb and ICA is aspirated at the conclusion of the procedure prior to balloon deflation.

Initial data in a multicenter, intention-to-treat trial, ARMOUR Trial(Proximal Protection with the MO.MA Device During Carotid Stenting), showed that the major 30-day event rate (major cardiac and cerebrovascular) was $2.7 \%$ and 30 -day major stroke rate was $0.9 \%$ in the patients undergoing CAS with MO.MA cerebral protection device. ${ }^{34}$

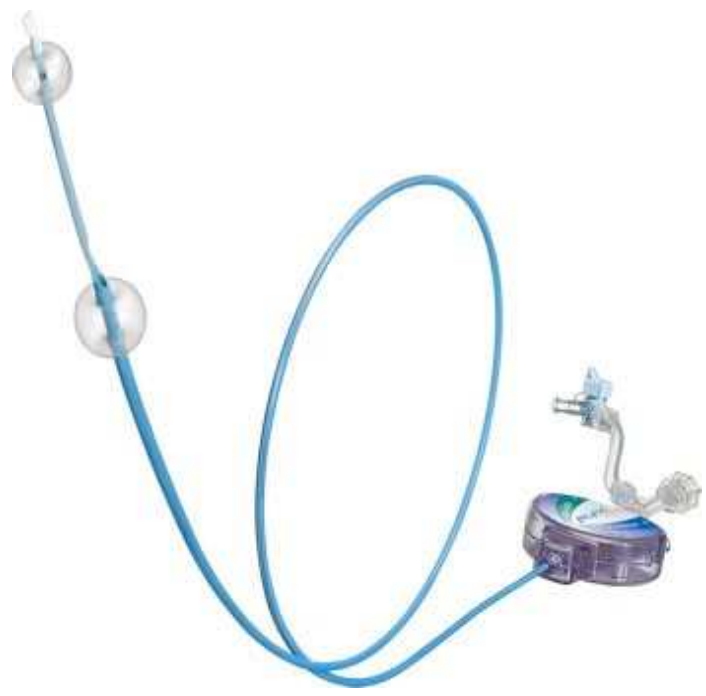

MO.MA device. (Source: Invatec Inc., Italy)

Flow reversal uses a similar principal of ECA and CCA occlusion during the angioplasty procedure but with dynamic flow reversal of blood from the carotid bulb into the femoral vein via a system side port. The flow reversal is encouraged by the higher arterial back pressure from the ICA compared to the venous system once the balloon system is inflated. This device is called the Parodi antiembolism system (PAES). Both devices serve the role of EPD as well as access sheath. 


\section{Neurorescue during carotid artery stenting}

\subsection{Procedural embolization}

Embolization can occur during the carotid artery stenting procedure and that can be in the form of micro- or macro-embolization. However, the risk of embolization is particularly high during the diagnostic phase, deployment of EPD period and during retrieval of the EPD. Most cases with micro-embolization are asymptomatic at the time of the procedure and in the immediate post-procedural phase, but their impact on long-term functional outcome (eg., cognitive function) is largely unknown.

The risk of embolization can be minimized by peri-procedural antiplatelet therapy (oral or intravenous GPIIB-IIIA inhibitors) and anticoagulation. These agents reduce platelet aggregation when subintimal tissue or stent material is exposed to the blood system during CAS. However, should macro-embolization occur, mainly due to technical error or failure of EPD, one should be prepared with mechanical retrieval/aspiration systems or catheterdirected thrombolysis.

\subsection{Thrombosis}

Thrombosis during the CAS procedure is associated with the use of EPDs. This is usually treated with direct aspiration of thrombus and/or direct administration of a thrombolytic (ie. Alteplase) or GPIIb-IIIa inhibitor intra-arterially, if possible. Also, distal embolization can be prevented by adopting an incomplete filter-retrieval technique in which case the filter retrieval system is not closed completely upon removal in order to prevent thrombus from being squeezed out of the system.

Acute stent thrombosis is rare $(<2 \%)$ and can be further minimized by appropriate periprocedural antiplatelet and anticoagulation strategy. The treatment consists of direct infusion of thrombolytic agent and/or GPIIb-IIIa inhibitor. This latter maneuver must be weighed against the risk of precipitating embolization during the lysis of an established ICA clot. In rare circumstances, when endoluminal techniques fail, the patient should immediately be taken to operating room and thrombectomy should be performed after appropriate anticoagulation and obtaining distal control to prevent progression of thrombosis and distal embolization.

\subsection{Dissection}

Dissection is fortunately a rare phenomenon and is usually related to stent insertion and/or balloon dilation. If the dissection does not limit the flow-lumen significantly, "wait-andobserve" strategy can be employed with or without use of continued anticoagulation. In case of significant flow-limiting dissection, the deployment of second stent may be advocated versus open surgical repair.

\section{CAS surveillance}

\subsection{Carotid restenosis}

The need for post-procedure surveillance is typically recommended by physicians who perform CAS. Surveillance options include duplex ultrasound (DU), MRA and CTA. MRA suffers from signal degradation due to the presence of a metallic stent and CTA involves significant ionizing radiation and the use of iodinated contrast, which may cause nephrotoxicity and allergic reactions ${ }^{35}$. Consequently, because of the absence of risk, DU surveillance after CAS has become the standard. 
Post-procedure sonography is performed in order to (1) identify undetected procedural faults associated with residual stenosis, (2) evaluate the occurrence of neointimal hyperplasia at the stented site, and (3) monitor the progression of contralateral disease. The incidence of significant contralateral disease ranges $25-50 \%$ making this the most compelling reason for ongoing duplex surveillance. Assessment of restenosis at the angioplasty site represents the second most frequent need for longitudinal surveillance.

Risk factors for restenosis after CAS largely remain undefined. When various factors are analyzed, a history of head and neck cancer and prior carotid endarterectomy (CEA) were found to be marginally significant for the development of early in-stent restenosis (ISR).36,37 The time line for the occurrence of ISR is somewhat variable but the majority $(>70 \%)$ of these cases are identified within 12 months following the index procedure ${ }^{3}$. However, this disease process may be ongoing as evidenced by an increasing incidence over a five year follow-up. Lal et al ${ }^{38}$, reported ISR rates of $2.7 \%$ and $6.4 \%$ at 1 and 5 years, respectively. These data utilize $80 \%$ stenosis as a measure of disease with this frequency rising if lower degrees of restenosis criteria are selected. Interestingly, ISR may regress over time but the temporal profile of this process as well as factors predictive of regression remain undefined.

\subsection{Duplex ultrasound criteria}

The baseline post-procedural duplex velocities for stented vessels tend to exhibit higher values than unstented vessels of normal luminal caliber. This may result from either under dilatation of the ICA during CAS or a change in the mechanical properties of the ICA. A common notion is that the purpose of balloon dilatation is to ensure an adequate ICA lumen and not an anatomically cosmetic perfect result. This conservative approach may predispose to a minor residual stenosis exemplified by a peak systolic velocity (PSV) higher than normal. Alternatively, some authorities have reported that the introduction of a stent into the carotid bulb and ICA alters the biomechanical properties of the vessel resulting in a stent-arterial complex with decreased compliance. This translates into an elevated PSV because energy normally applied to dilate the artery is now expended as increased flow velocity ${ }^{39}$. Consequently, recommendations have been advocated for the increase of velocity criteria corresponding to higher degrees of stenosis following CAS. Table 3 shows current recommendations by several clinical laboratories.

The variability of the recommended criteria values depends upon the balance between sensitivity and specificity desired by the laboratory performing the studies. Surveillance is usually performed every six months following CAS for at least two years. If the patient exhibits contralateral disease, this surveillance may be continued indefinitely.

\begin{tabular}{|cccc|}
\hline Stenosis & PSV $(\mathrm{cm} / \mathrm{sec})$ & EDV $(\mathrm{cm} / \mathrm{sec})$ & ICA/CCA ratio \\
\hline$>50 \%$ & $>225$ & - & $>2.5^{40}$ \\
\hline & $>240$ & - & $>2.45^{42}$ \\
\hline & & & - \\
\hline$>70 \%$ & $>170$ & $>120^{41}$ & $>4.75^{40}$ \\
\hline & $>350$ & - & $>4.3^{42}$ \\
\hline & $>450$ & - & \\
\hline & & & $>4.15^{38}$ \\
\hline$>80 \%$ & $>340$ & - & $>4.5339$ \\
\hline & $>325$ & $>119$ &
\end{tabular}

PSV=peak systolic velocity; EDV=end diastolic velocity

Table 3. Recommended Velocity Criteria for Restenosis of the ICA following CAS 


\section{Conclusion}

Carotid angioplasty and stenting is very slowly increasing in popularity. Currently, approximately $12 \%$ of carotid interventions in the United States involve CAS. The major limitation in its adaption is the reimbursement climate. Presently, the Center for Medicare Services restricts reimbursement for CAS to high risk, symptomatic patients (stenosis $>50 \%$ ) and high risk asymptomatic patients (stenosis $>80 \%$ ) who are on a clinical trial or registry. At least one private insurance carrier has elected to support payment for high risk asymptomatic patients $(>80 \%)$ indicating that reimbursement restrictions are gradually relaxing. Furthermore, the FDA has approved the use of the Acculink/Accunet carotid stent system in asymptomatic patients. These changes in regulatory requirements for CAS suggest that eventually, in the not too distant future, this procedure will be approved for all patients exhibiting carotid stenosis. Whether CAS should be performed in asymptomatic patients remains a controversial issue and will remain a topic in evolution as pharmaceutical therapy and life-style changes become increasingly aggressive.

\section{References}

[1] North American Symptomatic Carotid Endarterectomy Trial Collaborators, Beneficial effect of carotid endarterectomy in symptomatic patients with high grade carotid stenosis. N Engl J Med. 1991 Aug 15;325(7):445-53

[2] Endarterectomy for asymptomatic carotid artery stenosis. Executive Committee for the Asymptomatic Carotid Atherosclerosis Study. JAMA. 1995 May 10;273(18):1421-8.

[3] European Carotid Surgery Trialists' Collaborative Group, Ran-domised trial of endarterectomy for recently symptomatic carotid stenosis: final results of the MRC European Carotid Surgery Trial (ECST). Lancet. 1998 May 9;351(9113):1379-87.

[4] Robicsek F, Roush TS, Cook JW, Reames MK. From Hippocrates to Palmaz-Schatz, the history of carotid surgery. Eur J Vasc Endovasc Surg. 2004 Apr;27(4):389-97.

[5] Morris GC Jr, Lechter A, DeBakey ME. Surgical treatment of fibromuscular disease of the carotid arteries. Arch Surg. 1968 Apr;96(4):636-43.

[6] Mathias K. [A new catheter system for percutaneous transluminal angioplasty (PTA) of carotid artery stenoses]. Fortschr Med. 1977 Apr 21;95(15):1007-11. German.

[7] Diethrich EB, Ndiaye M, Reid DB. Stenting in the Carotid artery. Initial experience in 110 patients. J Endovasc Surg. 1996 Feb;3(1):42-62.

[8] Hammer FD, Lacroix V, Duprez T, et al: Cerebral microembolization after protected carotid artery stenting in surgical high-risk patients: Results of a 2-year prospective study. J Vasc Surg 2005;42:847-53.

[9] Dahn M, Cheema M, Bozeman P, Divinagracia T. Crossing an ultracritical carotid stenosis for carotid angioplasty. Vasc Endovascular Surg. 2009 Dec;43(6):589-91. Epub 2009 Oct 14.

[10] Mathias K. [A new catheter system for percutaneous transluminal angioplasty (PTA) of carotid artery stenoses]. Fortschr Med. 1977 Apr 21;95(15):1007-11. German.

[11] Bockenheimer SA, Mathias K. Percutaneous transluminal angioplasty in arteriosclerotic internal carotid artery stenosis. AJNR Am J Neuroradiol. 1983 May-Jun;4(3):791-2.

[12] Markus HS, Clifton A, Buckenham T, Brown MM. Carotid angioplasty. Detection of embolic signals during and after the procedure. Stroke. 1994 Dec;25(12):2403-6.

[13] Diethrich EB, Ndiaye M, Reid DB. Stenting in the Carotid artery. Initial experience in 110 patients. J Endovasc Surg. 1996 Feb;3(1):42-62. 
[14] Roubin GS, Yadav S, Iyer SS, Vitek J. Carotid stent-supported angioplasty: a neurovascular intervention to prevent stroke. Am J Cardiol. 1996 Aug 14;78(3A):8-12.

[15] Gil-Peralta A, Mayol A, Marcos JR, Gonzalez A, Ruano J, Boza F, Duran F. Percutaneous transluminal angioplasty of the symptomatic atherosclerotic carotid arteries. Results, complications, and follow-up. Stroke. 1996 Dec;27(12):2271-3.

[16] Yadav JS, Roubin GS, King P, Iyer S, Vitek J. Angioplasty and stenting for restenosis after carotid endarterectomy. Initial experience. Stroke. 1996 Nov;27(11):2075-9.

[17] Jordan WD Jr, Schroeder PT, Fisher WS, McDowell HA. A comparison of angioplasty with stenting versus endarterectomy for treatment of carotid artery stenosis. Ann Vasc Surg. 1997 Jan;11(1):2-8.

[18] Vozzi CR, Rodriguez AO, Paolantonio D, Smith JA, Wholey MH. Extracranial carotid angioplasty and stenting. Initial results and short term follow-up. Tex Heart Inst J. 1997;24(3):167-72.

[19] Teitelbaum GP, Lefkowitz MA, Giannotta SL Carotid angioplasty and stenting in highrisk patients. Surg Neurol. 1998 Oct;50(4):300-11; discussion 311-2.

[20] Brown MM. Balloon angioplasty for cerebrovascular disease. Neurol Res 1992; 14(suppl): 159-173

[21] Wholey MH, Wholey M, Bergeron P, Diethrich EB, Henry M, Laborde JC, Mathias K, Myla S, Roubin GS, Shawl F, Theron JG, Yadav JS, Dorros G, Guimaraens J, Higashida R, Kumar V, Leon M, Lim M, Londero H, Mesa J, Ramee S, Rodriguez A, Rosenfield K, Teitelbaum G, Vozzi C. Current global status of carotid artery stent placement. Cathet Cardiovasc Diagn. 1998 May;44(1):1-6.

[22] Theron JG, Payelle GG, Coskun O, Huet HF, Guimaraens L. Carotid artery stenosis: treatment with protected balloon angioplasty and stent placement. Radiology. 1996 Dec;201(3):627-36.

[23] Zarins CK, White RA, Diethrich EB, Shackelton RJ, Siami FS; CaRESS Steering Committee and CaRESS Investigators. Carotid revascularization using endarterectomy or stenting systems (CaRESS): 4-year outcomes. J Endovasc Ther. 2009 Aug;16(4):397-409.

[24] Sivaguru A, Venables GS, Beard JD, Gaines PA. European Carotid Angioplasty Trial. J Endovasc Surg. 1996 Feb;3(1):16-20.

[25] Naylor AR, Bolia A, Abbott RJ, Pye IF, Smith J, Lennard N, Lloyd AJ, London NJ, Bell PR. Randomized study of carotid angioplasty and stenting versus carotid endarterectomy: a stopped trial. J Vasc Surg. 1998 Aug;28(2):326-34.

[26] Alberts MJ. Results of a multicenter prospective randomized trial of carotid artery stenting vs. carotid endarterectomy. Stroke 2001.

[27] Yadav JS, Wholey MH, Kuntz RE, Fayad P, Katzen BT, Mishkel GJ, Bajwa TK, Whitlow P, Strickman NE, Jaff MR, Popma JJ, Snead DB, Cutlip DE, Firth BG, Ouriel K; Stenting and Angioplasty with Protection in Patients at High Risk for Endarterectomy Investigators. Protected carotid-artery stenting versus endarterectomy in high-risk patients. N Engl J Med. 2004 Oct 7;351(15):1493-501.

[28] Eckstein HH, Ringleb P, Allenberg JR, Berger J, Fraedrich G, Hacke W, Hennerici M, Stingele R, Fiehler J, Zeumer H, Jansen O. Results of the Stent-Protected Angioplasty versus Carotid Endarterectomy (SPACE) study to treat symptomatic stenoses at 2 years: a multinational, prospective, randomised trial. Lancet Neurol. 2008 Oct;7(10):893-902. Epub 2008 Sep 5. Erratum in: Lancet Neurol. 2009 Feb;8(2):135.

[29] Mas JL, Trinquart L, Leys D, Albucher JF, Rousseau H, Viguier A, Bossavy JP, Denis B, Piquet P, Garnier P, Viader F, Touzé E, Julia P, Giroud M, Krause D, Hosseini H, Becquemin JP, Hinzelin G, Houdart E, Hénon H, Neau JP, Bracard S, Onnient Y, 
Padovani R, Chatellier G; EVA-3S investigators. Endarterectomy Versus Angioplasty in Patients with Symptomatic Severe Carotid Stenosis (EVA-3S) trial: results up to 4 years from a randomised, multicentre trial. Lancet Neurol. 2008 Oct;7(10):885-92. Epub 2008 Sep 5.

[30] International Carotid Stenting Study investigators, Ederle J, Dobson J, Featherstone RL, Bonati LH, van der Worp HB, de Borst GJ, Lo TH, Gaines P, Dorman PJ, Macdonald S, Lyrer PA, Hendriks JM, McCollum C, Nederkoorn PJ, Brown MM. Carotid artery stenting compared with endarterectomy in patients with symptomatic carotid stenosis (International Carotid Stenting Study): an interim analysis of a randomised controlled trial. Lancet. 2010 Mar 20;375(9719):985-97. Epub 2010 Feb 25.

[31] Bonati LH, Fraedrich G; Carotid Stenting Trialists' Collaboration. Age modifies the relative risk of stenting versus endarterectomy for symptomatic carotid stenosis--a pooled analysis of EVA-3S, SPACE and ICSS. Eur J Vasc Endovasc Surg. 2011 Feb;41(2):153-8. Epub 2011 Jan 26.

[32] Brott TG, Hobson RW, Howard G, Roubin GS, Clark WM, Brooks W, et al: Stenting versus endarterectomy for treatment of carotid artery stenosis. $\mathrm{N}$ Engl J Med 2010;363:11-23.

[33] Reimers B, Corvaja N, Moshiri S, Saccà S, Albiero R, Di Mario C, Pascotto P, Colombo A. Cerebral protection with filter devices during carotid artery stenting. Circulation. 2001 Jul 3;104(1):12-5.

[34] Ansel GM, Hopkins LN, Jaff MR, Rubino P, Bacharach JM, Scheinert D, Myla S, Das T, Cremonesi A; Investigators for the ARMOUR Pivotal Trial. Safety and effectiveness of the INVATEC MO.MA proximal cerebral protection device during carotid artery stenting: results from the ARMOUR pivotal trial. Catheter Cardiovasc Interv. 2010 Jul 1;76(1):1-8.

[35] Rizzo JA, Dodge A, White P, Martin ED. Magnetic resonance angiography in the evaluation of carotid stent patency. Perspect Vasc Surg Endovasc Ther 2010;22:261-3.

[36] Skelly CL, et al. Risk factors for restenosis after carotid artery angioplasty and stenting. J Vasc Surg 2006;44:1010-5.

[37] Zhou W, et al. Management of in-stent restenosis after carotid artery stenting in high risk patients. J Vasc Surg 2006;43:305-12.

[38] Lal BK, et al. In-stent recurrent stenosis after carotid artery stenting: Life table analysis and clinical relevance. J Vasc Surg 2003;38:1162-9.

[39] Abu Rahma AF, et al. Optimal carotid duplex velocity criteria for defining the severity of carotid in-stent restenosis. J Vasc Surg 2008;48:589-94.

[40] Stanziale SF, et al. Determining in-stent restenosis of carotid arteries by duplex ultrasound criteria. J Endovasc Ther 2005;12:346-53.

[41] Peterson BG, et al. Duplex ultrasound remains a reliable test even after carotid stenting. Ann Vasc Surg 2005;19:793-7.

[42] Chi YN, White CJ, Woods TC, Goldman CK. Ultrasound velocity criteria for carotid instent restenosis. Catheter Cardiovasc Interv 2006;69:349-54. 


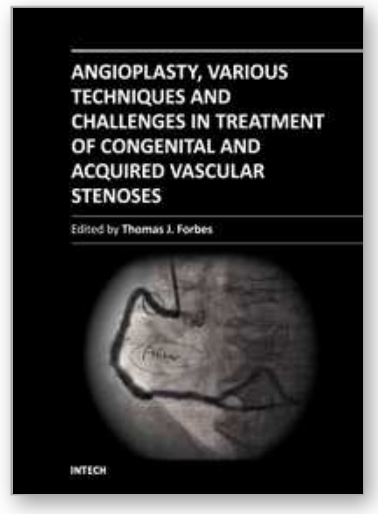

\section{Angioplasty, Various Techniques and Challenges in Treatment of Congenital and Acquired Vascular Stenoses}

Edited by Dr. Thomas Forbes

ISBN 978-953-51-0084-3

Hard cover, 236 pages

Publisher InTech

Published online 14, March, 2012

Published in print edition March, 2012

The field of performing transcatheter interventions to treat vascular lesions has exploded over the past 20 years. Not only has the technology changed, especially in the arena of balloon/stent devices, but the techniques of approaching complex lesions has evolved over the past decade. Lesions that no one would have imagined treating back in the 1990's are now being done routinely in the catheterization suite. This book provides an update on the current techniques and devices used to treat a wide variety of lesions. Though, at first, the outward appearance of the topics appears to be varied, they are all related by the common thread of treating vascular lesions. We hope, by publishing this book, to accomplish two things: First, to offer insight from experts in their field to treat, both medically and procedurally, complex vascular lesions that we frequently encounter. Secondly, we hope to promote increased communication between areas of medicine that frequently don't communicate, between adult interventional cardiologists, pediatric interventional cardiologists, interventional radiologists, and neurosurgeons. Much can be learned from our respective colleagues in these areas which can further our own world of interventions.

\section{How to reference}

In order to correctly reference this scholarly work, feel free to copy and paste the following:

Parth Shah and Michael Dahn (2012). Carotid Angioplasty, Angioplasty, Various Techniques and Challenges in Treatment of Congenital and Acquired Vascular Stenoses, Dr. Thomas Forbes (Ed.), ISBN: 978-953-51-00843, InTech, Available from: http://www.intechopen.com/books/angioplasty-various-techniques-and-challengesin-treatment-of-congenital-and-acquired-vascular-stenoses/carotid-angioplasty

\section{INTECH}

open science | open minds

\section{InTech Europe}

University Campus STeP Ri

Slavka Krautzeka 83/A

51000 Rijeka, Croatia

Phone: +385 (51) 770447

Fax: +385 (51) 686166

www.intechopen.com

\section{InTech China}

Unit 405, Office Block, Hotel Equatorial Shanghai

No.65, Yan An Road (West), Shanghai, 200040, China

中国上海市延安西路65号上海国际贵都大饭店办公楼405单元

Phone: +86-21-62489820

Fax: $+86-21-62489821$ 
(C) 2012 The Author(s). Licensee IntechOpen. This is an open access article distributed under the terms of the Creative Commons Attribution 3.0 License, which permits unrestricted use, distribution, and reproduction in any medium, provided the original work is properly cited. 